\title{
Framed mode choice experiment for analysing commuter behaviour
}

\author{
Created by: Bhuvanachithra Chidambaram ${ }^{1}$ \\ 1, Research Associate, TU Dortmund University, Germany; bhuvigna@gmail.com
}

Version received: 10 June 2020

check for

updates

\begin{abstract}
Lack of travel demand measures to curb private vehicles in the city, leading to the problem of traffic congestion in the emerging megacities. Analysis of the problem of traffic congestion to commuter travel mode preferences in the city opens up the door for theoretical exploration of the process of traffic congestion. The study reports the analysis of the framed field experiment to investigate the behavioural responses of commuters. By involving 204 commuters, the research is aimed to investigate the behavioural response of commuters if demand-based non-technical measures are implemented as treatments in the experiment. The two central questions related to this objective are: how do commuter travel mode preferences contribute to urban traffic congestion? And, how can this be empirically analysed in terms of the effect of demand-based non-technical measures?
\end{abstract}

\section{Introduction}

Urban traffic is determined by traffic-flow parameters such as vehicle speed $(v)$, traffic flow $(q) \stackrel{[1]}{\text { and }}$ density $(k)[2]$. Figure 1 shows the non-linear relation between traffic flow and density, categorised into three stages: free flow, stable flow and forced flow. The phase from free flow to stable flow is called the free-flow phase (i.e. from $q_{0}$ to $q_{\max }$ ). Traffic flow increases along with density until reaching a saturation point $\left.\left(k_{o p}, q_{\max }\right){ }^{[3}\right]$. During this phase, self-interested commuters choosing the dominant strategy of taking their private vehicles (e.g. car) can enjoy the benefits of relatively high speeds, saving travel time, comfort and convenience, irrespective of the action of other commuters. This is, however, in conflict with the common interest of taking public buses and thus results in a social dilemma. Moreover, private vehicle drivers contribute towards negative impacts for other road users in the form of vehicle emissions in the air. Joint efforts by the entire group of individuals towards achieving improved air quality consequently fails due to the opportunistic behaviour of some rational commuters, thus leading to a collaboration problem in this phase.

The subsequent increase of additional private vehicles directs the traffic flow from stable to a forced flow $\left(q_{\max }\right.$ to $\left.q_{o}\right)$, that is, the number of vehicles exceeds the optimal capacity and ends in a jamming concentration $\left(k_{\max }\right)$. This indicates the formation of vehicle stagnation or queuing, commonly known as traffic congestion. During this phase, taking a private car is no longer a dominant strategy for commuters as they now bear social costs with other road users in the form of traffic congestion and associated time delays. Here, the outcome for an individual not only depends on his or her preferences concerning travel mode, but also on the preferences of others. In other words, an individual could enjoy the best strategy of taking private car only if others in the group prefer the optimal strategy of taking public buses and this interdependency leading to coordination problem in this phase. 


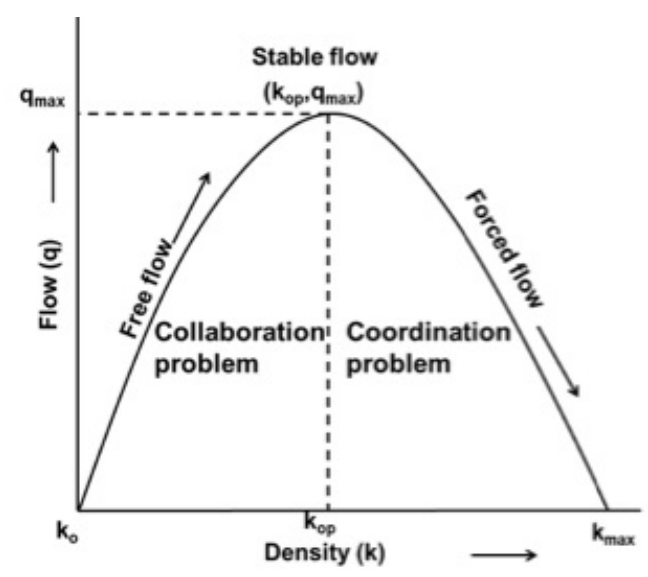

Figure 1. Traffic flow function- coordination problem.

In the viewpoint of game theory, commuters travel mode choice is perceived as a coordination problem between private and public transport. Coordination problems have been widely studied under lab conditions in macroeconomics. Players (actors) in such games are often observed to be free-riding resources without incurring any personal costs. This kind of behaviour leads to the 'tragedy of commons' situation in the resource dilemma and environmental problems in the public goods

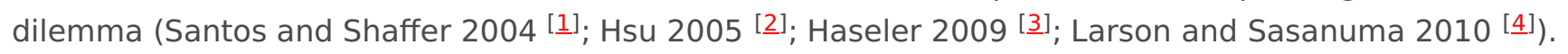
Coordination problems are situations where actors have a common interest in avoiding particular outcome, termed a 'dilemma of common aversion' (Stein 1982 [ㄷ]; Dombrowsky 2007 []]; de Bettignies and Lépineux $2009^{[]}$).

Developing a theoretical understanding of urban traffic flows through the lens of game-theory reveals the relation between commuter mode choice and traffic congestion as a coordination problem between commuters. This theoretical insight then guides a discussion of transport institutions, emphasizing demand-based non-technical measures as a way to minimise this coordination problem. On this theoretical basis, an experimental model is developed and hypotheses regarding the effectiveness of three important demand-based measures for minimising the coordination problem are tested by conducting a framed field experiment with commuters.

\section{Method}

The experimental economics approach because of its two main advantages over discrete choice models: i) observed behavioural patterns of commuters other than the hypothetical behaviour; and ii) the possibility of repeated interactions between commuters and institutions, which could help one to observe such behavioural patterns. Accordingly, a framed field mode choice experiment was designed and employed with real-world commuters. The main aim of the experiment was to explore the effect of demand-based traffic strategies to reduce the coordination problem among commuters in choosing between private and public modes of transport. Three demand-based traffic strategies involving three mechanisms-such as an incentive (bus subsidy), disincentive (parking cost) and persuasive (public coordination) measures-have been adopted.

The experiment was a coordination game with $\mathrm{n}(=6)$ players who each make a choice to use the bus $(\mathrm{x}$ $=0$ ) or car $(x=1)$ for commuting. The payoff for the individual player depends on their own decisions and those of the other players. The social optimum is to have one car and five participants on the bus. Note that the individual in the car will have a higher payoff in the social optimum. Therefore, the social optimum is unstable. If players are selfish and rational and expect that others are too, they will choose the car if they expect there are zero, one or two other participants choosing it. If participants expect three or four other participants to choose the car, choosing the bus leads to better earnings. The participant is indifferent if she expects all others to choose the car. Hence, there are various Nash equilibria, dependent on the expectations of the participants. 
Results were announced to all players after each round, though maintaining the anonymity of their choices. Subjects were not allowed to talk, and they were seated in a way that they could not directly see each other. A short general introduction was given by a facilitator. After questions from players were answered, subjects then received written instructions for the first exercise. After completion, instructions for the next exercise were distributed. Following the experiment, a brief survey was conducted which contained questions on the socio-economic background of participants, their everyday traffic behaviour and their attitudes regarding different policy measures and traffic-related problems.

\section{Results}

Figure 2 shows the results of the treatment effects of the experiment. In the baseline condition, we see an increase in car usage over the bus. Initially, about two of the participants chose a car on average. Introduction of the bus subsidy or parking fee initially has a positive effect on the group, but over time, we see an increase in choosing the car. Introducing the treatments reduces the number of cars relative to the baseline. The pecuniary treatments show a larger decrease in the number of cars chosen as compared to the public coordination condition.

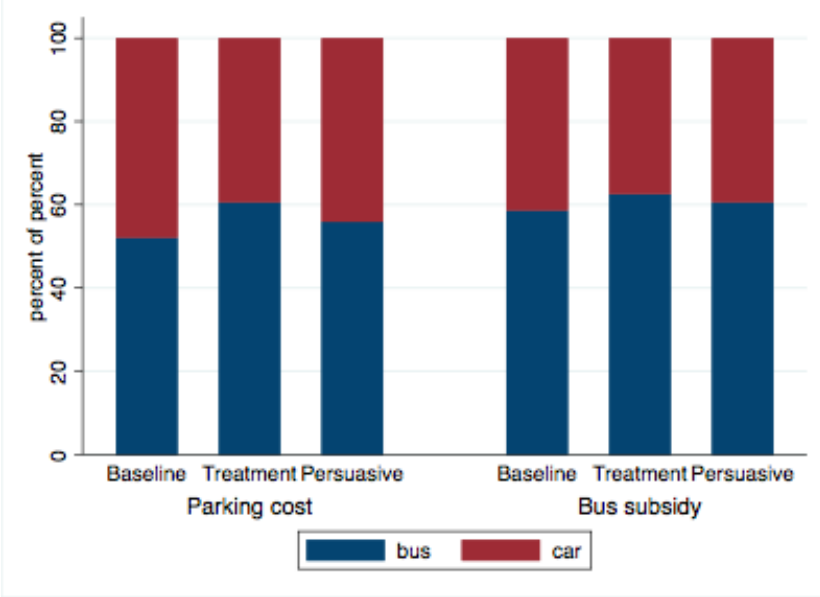

Figure 2. Treatment effects in the experiment.

The results show that the introduced treatments induce a modest increase in choosing the bus in the game. Increasing the parking costs or subsidizing the bus in the game has a positive effect. Table 1 shows the mean earnings of the participants in points. Higher the points, then individuals are facing the free flow traffic whereas the lower points indicate the state of traffic congestion. Compared to other measures, parking cost measures can be seen increasing total earnings for both users. This fairly indicates that parking cost measures when implemented beneficial for both private and public transport users in alleviating traffic congestion. For more about this field experiment, pls. see (Chidambaram et al. 2014 ) [].

Table 1. Mean Earnings (points) in the experiment.

\begin{tabular}{|l|l|l|}
\hline & $\begin{array}{l}\text { Car as mode } \\
\text { mean points } \\
(\mathrm{sd})\end{array}$ & $\begin{array}{l}\text { Bus as mode } \\
\text { mean } \\
\text { points (sd) }\end{array}$ \\
\hline $\begin{array}{l}\text { Parking cost } \\
\text { measures }\end{array}$ & $15.22(5.64)$ & $\begin{array}{l}14.59 \\
(3.41)\end{array}$ \\
\hline $\begin{array}{l}\text { Bus subsidy } \\
\text { measures }\end{array}$ & $11.11(5.63)$ & $\begin{array}{l}12.95 \\
(1.82)\end{array}$ \\
\hline
\end{tabular}




\begin{tabular}{l|l|l} 
Persuasion & & 12.47 \\
measures & $14.43(4.17)$ & $(1.59)$
\end{tabular}

\section{Conclusion}

The results show that the introduced treatments induce a modest increase in choosing the bus in the game. Increasing the parking costs or subsidizing the bus in the game has a positive effect. The nonpecuniary treatment, the persuasive measure is a little less effective in reducing the number of cars, yet significantly increases participants' earnings because of enhanced coordination.

The experiment highlights the interdependence effect within groups, i.e. participants made their own decisions based on the expected decisions of others. It is observed that participants chose the car less frequently when a monetary incentive for using public transport or avoiding the car is introduced. Notably, it is also observed that providing information to facilitate coordination helped subjects to improve their earnings. Thus the experiment disentangles complex causal relationships by testing traffic policies in the field under controlled conditions. In this way, experimental research in transportation economics could generate further interesting insights for demand-side measure policy debates and enrich the current discourses therein.

\section{Endnote}

[1] Traffic flow, also known as traffic volume, is defined as the number of vehicles expressed in terms of passenger car units passing a specified point during a stated period of time.

[2] Density, also known as concentration, is defined as the number of passenger car units present in a stated length of road at any given time.

[3] This indicates that the traffic flow $(q)$ is stable, as it has reached the optimal capacity of the road $\left(k_{\mathrm{op}}\right)$. Technically, roads should be built at this optimal road capacity $\left(k_{\mathrm{op}}\right)$.

\section{References}

1. Santos, G; Shaffer, B; Preliminary Results of the London Congestion Charging Scheme. Public Works Management \& Policy 2004, 9, 164-181, 10.1177/1087724x04268569.

2. Hsu, S.L; What is a Tragedy of the Commons? Overfishing and the Campaign Spending Problem. Albany Law Review 2005, 69(1), 75-138.

3. Haseler, C.; The Tragedy of the Commons in Traffic Routing and Congestion.. Structure 2009, 1, 1-7.

4. Larson, R.C and Sasanuma, K; Urban Vehicle Congestion Pricing: A Review. Journal of Industrial and Systems Engineering 2010, 3, 227-242.

5. Stein, A.; Coordination and collaboration: regimes in an anarchic world. International Organization 1982, 36, 299324, 10.1017/s0020818300018968.

6. Dombrowsky, I.. Conflict, Cooperation, and Institutions in International Water Management: An Economic Analysis; Edward Elgar: Great Britain, 2007; pp. 78.

7. de Bettignies, H.C and Lepineux. Business, Globalization, and the Common Good.; International Academic Publishers: Germany, 2009; pp. 89.

8. Chidambaram, B; Janssen, M; Rommel, J; Zikos,D; Commuters' mode choice as a coordination problem: A framed field experiment on traffic policy in Hyderabad, India. Transportation Research Part A: Policy and Practice2014, 65, 9-22, 10.1016/j.tra.2014.03.014.

\section{Keywords}

commuting; TDM; interdependence; coordination; game theory; parking; bus subsidy; learning 